\title{
DOES JOB BURNOUT MEDIATE NEGATIVE EFFECTS OF JOB DEMANDS ON MENTAL AND PHYSICAL HEALTH IN A GROUP OF TEACHERS? TESTING THE ENERGETIC PROCESS OF JOB DEMANDS-RESOURCES MODEL
}

\section{LUKASZ BAKA}

Jan Dlugosz University in Czestochowa, Częstochowa, Poland

Department of Psychology

\begin{abstract}
Objectives: The aim of the study was to investigate the direct and indirect - mediated by job burnout - effects of job demands on mental and physical health problems. The Job Demands-Resources model was the theoretical framework of the study. Three job demands were taken into account - interpersonal conflicts at work, organizational constraints and workload. Indicators of mental and physical health problems included depression and physical symptoms, respectively. Material and Methods: Three hundred and sixteen Polish teachers from 8 schools participated in the study. The hypotheses were tested with the use of tools measuring job demands (Interpersonal Conflicts at Work, Organizational Constraints, Quantitative Workload), job burnout (the Oldenburg Burnout Inventory), depression (the Beck Hopelessness Scale), and physical symptoms (the Physical Symptoms Inventory). The regression analysis with bootstrapping, using the PROCESS macros of Hayes was applied. Results: The results support the hypotheses partially. The indirect effect and to some extent the direct effect of job demands turned out to be statistically important. The negative impact of 3 job demands on mental (hypothesis $1-\mathrm{H} 1$ ) and physical (hypothesis $2-\mathrm{H} 2$ ) health were mediated by the increasing job burnout. Only organizational constraints were directly associated with mental (and not physical) health. Conclusions: The results partially support the notion of the Job Demands-Resources model and provide further insight into processes leading to the low well-being of teachers in the workplace.
\end{abstract}

Key words:

Job Demands-Resources Model, Job burnout, Job demands, Depression, Physical health

\section{INTRODUCTION}

The dynamic changes that occur in the world of work have posed new challenges for the occupational health research [1]. Several researchers have argued that the popular models of job stress (e.g., the Job Demands-Control model or the Effort-Reward Imbalance model) may have limitations in capturing the new, complex, and often specific determinants of job stress and occupational well-being $[2,3]$. For that reason more context-specific models of job stress have been developed recently.

One of them is the Job Demands-Resources model (JD-R) $[4,5]$. This model assumes that each workplace

This research was supported by the research grant DS/IFSIP/34/2013 awarded to the author.

Received: March 10, 2014. Accepted: September 19, 2014.

Corresponding author: Ł. Baka, Jan Dlugosz University in Czestochowa, Department of Social Sciences, Zbierskiego 2/4, 42-200 Częstochowa, Poland (e-mail: 1.baka@ajd.czest.pl; lukaszbaka@interia.pl). 
has its own set of job characteristics that determine employees' health and well-being. Job characteristics can be divided into job demands and job resources. According to the JD-R model, job demands are connected with ill health, whereas job resources are related to positive work attitudes. In addition to the research on the direct relationships between job demands and health problems, the JD-R model tries to identify the potential mediators and moderators engaged in the indirect effect of the relationship. The job burnout is one of the most frequently studied mediators in the context of the JD-R model. Several studies have confirmed that high job demands result in the job burnout and that, in turn, leads to health problems in different occupational groups, including teachers (the so-called energetic process) [6,7]. In these studies mental, and not physical health was mainly taken into account. This research is an attempt to verify the JD-R model in Polish conditions. It tests how the job burnout mediates the negative impact of job demands on mental (measured by depression) and physical health (measured by physical symptoms) in a group of teachers.

\section{The JD-R model}

\section{as the theoretical framework of the research}

In accordance with the JD-R model, each occupation contains specific job demands which, in the case of low job resources, may lead to poor health [5]. Job demands refer to those "physical, social or organizational job aspects that require sustained physical and/or psychological effort and are associated with certain physiological and/or psychological costs" [4]. They include stress, bad working conditions, job routine, workload, interpersonal conflicts and organizational constraints. Job resources are related to "physical, social and organizational aspects of the job, the physical, psychological, social or organizational aspects of which may: be functional in achieving work-related goals; reduce job demands and related physiological and psychological costs; stimulate personal growth and development" [4]. Numerous studies have confirmed that high job demands are directly related to low mental and physical health $[5,7]$. The scientists suggest that the main factors, that are responsible for it, include: job strain and deterioration of immunological system [8].

Previous studies also confirmed indirect effects of job demands on health problems $[6,7]$. They indicated that job demands trigger the energetic process that through high job burnout results in health problems. In line with the energetic process, high job demands induce a performance protection strategy that is connected with the mobilization of sympathetic activation (autonomic and endocrine), increase in a subjective effort (use of active control in information processing) or both of them. Frequent application of the strategy can lead to depletion of both physical and mental resources and may bring about job burnout. In the long time perspective, the job burnout may result in various psychosomatic disorders, including depression and somatic problems.

General assumptions of the JD-R model were supported in a number of studies in many different countries including Germany, the Netherlands, Greece, Finland, Spain and Austria, among such occupational groups as nurses, dentists, social workers, care service workers, white and blue collar workers, managers, air traffic controllers and teachers [9].

\section{Job demands and ill health}

The volume of research on occupational stress has increased in recent years because of growing awareness of the need to improve the quality of a workplace and wellbeing of employees. Although it has been suggested that job demands sometimes might be the source of challenges at work rather than a stressful aspect, job demands may become stressors, especially when they require high effort to sustain an expected performance level, consequently eliciting negative responses, including job burnout and depression [6]. In many previous studies on teachers 
the researchers have mainly dealt with job demands related to specific work of teachers, such as maintaining classroom discipline, aggression of pupils, coping with changes [10,11]. This study considers 3 more general job demands such as interpersonal conflicts at work, organizational constraints and quantitative workload. Each of them is identified as a serious source of psychological strain [12].

Interpersonal conflict at work is defined as a negative interpersonal encounter characterized by a contentious exchange, hostility or aggression. It may be an isolated incident or repeated and enduring acts which can be manifested as bullying. Interpersonal conflict at work may range from minor disagreements between colleagues to physical violence towards others [12]. The conflict may be overt (e.g., being rude to colleagues) or may be covert (e.g., spreading rumors about colleagues). The Stress Incident Report (SIR), an open-ended method used by Keenan et al. [13] to collect stressful incidents that occur at work, shows that $74 \%$ of the reported incidents are caused by social interactions with superiors, subordinates or colleagues. The previous research showed that interpersonal conflicts at work are positively co-related with employees' frustration, anxiety, anger, emotional exhaustion, job burnout and depression [14].

Organizational constraints are related to situations or things that prevent employees from translating ability and effort into a high level of job performance. These constraints may include faulty equipment, incomplete or poor information flow, as well as interruptions by others. $\mathrm{Nu}$ merous studies have found that organizational constraints are associated with employees' frustration, work anxiety, mental fatigue, job dissatisfaction, job burnout and physical symptoms [15].

Workload is listed as one of the most common sources of stress [13]. It may be measured by the number of working hours, production output, or even mental demands of the work being performed. Under this study, quantitative workload is provided, which is measured by the volume of work that employees are required to perform during a given time period [13]. Numerous research has supported the direct positive effects of quantitative workload on mental and physical ill health [16].

\section{Mediating role of job burnout}

The burnout syndrome has been described in literature for over 40 years. It has also been diagnosed by physicians and included in the ICD-10 Classification of Mental and Behavioral Disorders. In terms of the classic approach, job burnout has been defined as a psychological syndrome of 3 symptoms - emotional exhaustion, depersonalization and reduced personal accomplishment [17]. The authors of the JD-R model have proposed a new outlook of the job burnout, which is defined as a long-term effect of chronic work-related stress caused by excessive job demands and low job resources. Job burnout consists of 2 components exhaustion and disengagement from work. In comparison with the classic approach to exhaustion, the JD-R model underlines not only its emotional aspect, but also the physical and cognitive ones. Instead of depersonalization keeping emotional distance from a recipient - Demerouti et al. [4] use it to mean disengagement from work, which is defined as a distanced attitude to recipients, colleagues and the whole work-related context such as duties, workers' values, and organizational culture. Thus, disengagement is a broader notion which comprises both depersonalization and the lack of personal achievement [4].

Several studies conducted in the context of the JD-R model have found that job burnout mediates the relationships between different types of job demands and ill health. For example, the research conducted by Hakanen et al. has indicated that job burnout mediated negative impact of disruptive pupils' behavior, quantitative workload and poor physical working conditions on self-rated mental problems in a group of Finnish teachers [6]. Mediating function of the job burnout was supported also in the cross-lagged 
study, in which emotional demands, quantitative workload and poor working conditions led to depression through increasing high job burnout in the group of dentists [7].

To the best of my knowledge only 2 investigations tested the role of job burnout as a mediator of the link between job demands and physical health. They yielded incompatible results. In the Dutch study on workers of service organizations, Schaufeli et al. [18] have found that qualitative and quantitative workloads lead - through a high job burnout to psychosomatic symptoms, including headaches, cardiovascular problems and gastric problems. Whereas, another study did not confirm the mediating role of job burnout in the relationship between job demands and somatic ill health in the group of Austrian blue- and white- collar workers [19]. Although the studies on the job burnout in terms of the JD-R model have been conducted in Poland for example in a group of nurses [20] and teachers [21], the energetic process has not been checked in Polish studies yet. Relying on the studies referred to above, it seems likely that job demands affect both mental and physical health problems directly and indirectly, through job burnout. The research hypotheses are presented below:

- the hypothesis 1 (H1) - job demands are related to depression directly and indirectly through increasing job burnout,

- the hypothesis $2(\mathrm{H} 2)$ - job demands are related to physical ill health directly and indirectly through increasing job burnout.

\section{MATERIAL AND METHODS}

\section{Subject}

Polish teachers $(\mathrm{N}=316)$ from 8 elementary $(\mathrm{N}=83)$, gymnasium $(\mathrm{N}=62)$ and secondary $(\mathrm{N}=171)$ schools were participants of the study. The choice of the group has been influenced by the fact that teachers are described in psychological literature as a vocational group which is particularly vulnerable to job stress and job burnout. For example, Friedman et al. [22] have found that 5-25\% of American teachers have manifested symptoms of job burnout during their professional career. Dutch [18] and Finnish [6] researchers, in turn, have shown that teachers display the highest level of job burnout among the analyzed vocational groups (e.g., police officers, medical staff, care service staff). High job stress and job burnout among Polish teachers have been distinctly confirmed [10].

The study was conducted between February and May 2012. Participation in the study was voluntary. Potential respondents received a hard copy of the questionnaires along with the letter explaining the purpose of the study. Full confidentiality of data and anonymity were secured. The filled in questionnaires were put into envelopes and collected by the research assistants (i.e., 3 undergraduate students). All the participants were treated in conformity with the ethical guidelines of the Helsinki Declaration. Out of 400 distributed questionnaires, 331 (83\%) were returned and 316 ( $79 \%$ of the original pool) were completed in at least $85 \%$ and subsequently used for the data analysis purposes. The study group consisted of 250 (79\%) women and $66(21 \%)$ men, aged between 22 and 60 years old (mean $(M)=40.67$; standard deviation $(S D)=9.49)$. Professional experience ranged from 1 to 37 years $(\mathrm{M}=14.42$; $\mathrm{SD}=9.86$ ). Average weekly working time of the participants was $30 \mathrm{~h}$.

\section{Variables and diagnostic methods}

In this investigation 6 variables were included and measured with 6 standard examination tools - questionnaires. Three of them were used to measure job demands, namely: interpersonal conflicts, organizational constraints and quantitative workload. Single questionnaires were utilized to measure job burnout, depression and physical health.

\section{Job demands}

In order to measure this variable, 3 Polish versions of the scales were used i.e., the 4-item Interpersonal Conflicts at Work Scale (ICAWS), the 11-item Organizational 
Constraints Scale (OCS), and the 5-item Quantitative Workload Inventory (QWI). The scales were developed by Spector et al. [13]. Satisfactory statistical measures of the scales were obtained in the original study. They were also used successfully for the purpose of the Polish research on teachers [9]. The studies confirmed theoretical validity of the tools -3 that analyzed job demands were positively correlated with job stressors (e.g., work-family conflict) and negatively correlated with job resources (e.g., social support). In the current study the respective reliability coefficients - Cronbach's $\alpha$ - for the scales were: 0.79 for the ICAWS, 0.86 for the OCS, and 0.82 for the QWI.

\section{Job burnout}

The job burnout was measured with the Polish version of the Oldenburg Burnout Inventory (OLBI) by Demerouti et al. [23]. It consists of 2 subscales - exhaustion and disengagement from work, which are combined and form the general burnout coefficient. The correlation between the 2 job burnout subscales was $r=0.52$. The reliability coefficient for the general job burnout - Cronbach's $\alpha$ - ranged from 0.74 to 0.92 , depending on the study group. Theoretical validity was evidenced by a strong correlation with 3 job burnout symptoms measured with the Maslach Burnout Inventory the General Survey (MBI-GS) questionnaire [23]. The OLBI was used in several Polish studies [21,24]. Its theoretical validity was verified. Job burnout was positively correlated with job stress and negatively correlated with work engagement. In this study the confirmatory factor analysis pointed out one-factorial construction of the OLBI and for that reason general job burnout (and not separated components) was exclusively included for further analysis. The reliability coefficient for general job burnout was $\alpha=0.87$.

\section{Ill health}

The indicator of mental ill health was depression measured with the Polish version of the Beck Hopelessness Scale (BHS) [25]. The Beck Hopelessness Scale includes 20 items related to 3rd component of the depressive cognitive triad - negative and pessimistic outlook of one's future. In this study the reliability coefficient for the scale was $\alpha=0,77$.

Somatic ill health was measured with the Polish version of the Physical Symptoms Inventory (PSI) by Spector et al. [12]. It includes 18 positions related to physical symptoms such as headache, backache, eyes strain, stomach cramps, trouble sleeping, infection, skin rush, constipation. The task of the participants is to indicate the symptoms they had during the last month and which of them required medical counseling ( 0 - No; 1 - Yes, but I didn't see a doctor; 2 - Yes and I saw a doctor). The sum of points makes up a general indicator of physical health. The inventory was used in the previous Polish research, in which somatic health problems were correlated with job burnout and job stress [24]. It obtained satisfactory statistical measure, both in the original [13] and the current studies (Cronbach's $\alpha=0.84$ ).

\section{Statistical analysis}

The research model was tested by means of regression analysis with bootstrapping, using the PROCESS macros [26]. In comparison with the classic mediation analysis of Baron et al. [27], the PROCESS allows to test direct and indirect effects in one model. The Model 4 was applied to verify the research hypotheses (simple mediation). Applying bootstrapping (5000 samples), the PROCESS calculates direct, indirect and global effects as well as their confidence intervals. The direct effect refers to the link between independent and dependent variables and is estimated as the path c'. The indirect effect refers to the effect of the independent variable on the dependent variable through the mediator and is estimated as the paths $a$ and $b$. The path a relates to the effect of the independent variable on the mediator and the path $b$ refers to the effect of the mediator on the dependent variable controlling for the independent variable. The direct 
and indirect effects sum to yield the total effect. Talking about the existence of the mediation is allowed when the value of $B$ in the indirect effect is statistically significant. The mediation is additionally checked by means of the Sobel's test (value Z).

\section{RESULTS}

\section{Preliminary analyses}

Means, standard deviations and Pearson's correlations are displayed in the Table 1. Job burnout decreases along with age and job seniority. A greater number of work hours is accompanied by all 3 job strain outcomes: job demands, general job burnout, depression and physical symptoms. Two variables connected with ill health - depression and physical symptoms - are distinctly correlated.

\section{Testing the mediation model ( $\mathrm{H} 1, \mathrm{H} 2)$}

The Tables 2 and 3 include values of B-coefficient and confidence interval for direct, indirect and total effects. The direct effect of job demands on ill health is estimated with c', the indirect effect is estimated with a (the effect of job demands on job burnout) and $b$ (the effect of job burnout on poor health). The Figures 1-3 show the values of B-coefficients for a, b and c' paths in the analyzed links. The mediation analysis has found that high organizational constraints (but not interpersonal conflict and workload) are directly related to high depression (Table 1 , direct effect). This effect is shown on the Figure 2 (the upper line, path c'). As far as the indirect effect is concerned, the data shows that 3 analyzed job demands are predictors of job burnout, which in turn predicts a high level of depression (Table 1, indirect effect). The Figures 1-3 (the upper lines, paths $a$ and $b$ ) show that interpersonal conflict (Figure 1), organizational constraints (Figure 2) and workload (Figure 3) result in depression through increasing job burnout. This result partially confirms H1.

The analysis shows that none of the job demands is directly related to physical symptoms (Table 2 , direct effect), but indirect effects of 3 job demands (Table 2, indirect effect) are confirmed. It turns out that high job demands are predictors of high job burnout, which in turn is the predictor of frequent physical symptoms (Figures 1, 2 and 3, the

Table 1. Descriptive statistics and correlation coefficients between the variables

\begin{tabular}{|c|c|c|c|c|c|c|c|c|c|c|}
\hline \multirow{2}{*}{ Variable } & \multirow{2}{*}{$\mathrm{M} \pm \mathrm{SD}$} & \multicolumn{9}{|c|}{ Correlation } \\
\hline & & 1 & 2 & 3 & 4 & 5 & 6 & 7 & 8 & 9 \\
\hline 1. Age & $40.67 \pm 9.48$ & - & & & & & & & & \\
\hline 2. Gender & - & $-0.17^{* *}$ & - & & & & & & & \\
\hline 3. Job seniority & $14.42 \pm 9.86$ & $0.85^{* * *}$ & $-0.14^{*}$ & - & & & & & & \\
\hline 4. Work hours & $30.14 \pm 10.66$ & 0.04 & -0.07 & -0.05 & - & & & & & \\
\hline $\begin{array}{l}\text { 5. Interpersonal } \\
\text { conflicts }\end{array}$ & $1.29 \pm 0.45$ & -0.03 & -0.04 & -0.08 & $0.30^{* * *}$ & - & & & & \\
\hline $\begin{array}{l}\text { 6. Organizational } \\
\text { constraints }\end{array}$ & $1.67 \pm 0.59$ & $-0.19^{* *}$ & 0.06 & $-0.18^{* *}$ & $0.27^{* * *}$ & $0.44^{* * *}$ & - & & & \\
\hline 7. Workload & $3.21 \pm 0.87$ & 0.10 & 0.02 & -0.08 & $0.26^{* * *}$ & $0.28^{* * *}$ & $0.40^{* * *}$ & - & & \\
\hline 8. Job burnout & $2.21 \pm 0.54$ & $-0.14^{*}$ & -0.11 & $-0.12^{*}$ & $0.31^{* * *}$ & $0.36^{* * *}$ & $0.48^{* * *}$ & $0.24^{* * *}$ & - & \\
\hline 9. Depression & $0.48 \pm 0.25$ & -0.07 & -0.11 & -0.04 & $0.20^{* * *}$ & $0.16^{* *}$ & $0.29 * * *$ & $0.15^{* *}$ & $0.64 * * *$ & - \\
\hline $\begin{array}{l}\text { 10. Physical } \\
\text { symptoms }\end{array}$ & $0.41 \pm 0.31$ & 0.05 & -0.04 & 0.06 & $0.19^{* * *}$ & $0.22^{* * *}$ & $0.26^{* * *}$ & $0.14^{*}$ & $0.42^{* * *}$ & $0.40^{* * *}$ \\
\hline
\end{tabular}

$\mathrm{M}$ - mean; SD - standard deviation.

$* \mathrm{p}<0.05 ;{ }^{* *} \mathrm{p}<0.01 ;{ }^{* * *} \mathrm{p}<0.001$. 
Table 2. Total, direct and indirect effects of job demands on depression

\begin{tabular}{|c|c|c|c|c|c|c|c|c|c|}
\hline \multirow{3}{*}{ Effect } & \multicolumn{9}{|c|}{ Depression as a dependent variable } \\
\hline & \multicolumn{3}{|c|}{ interpersonal conflict at work ${ }^{\mathrm{a}}$} & \multicolumn{3}{|c|}{ organizational constraints $^{\mathrm{b}}$} & \multicolumn{3}{|c|}{ quantitative workload ${ }^{c}$} \\
\hline & $\mathrm{B}$ & SE & $95 \% \mathrm{CI}$ & B & SE & $95 \% \mathrm{CI}$ & B & SE & $95 \% \mathrm{CI}$ \\
\hline Total & $0.39^{* * *}$ & 0.09 & $0.21-0.57$ & $0.49^{* * *}$ & 0.06 & $0.37-0.62$ & $0.19 * * *$ & 0.05 & $0.09-0.28$ \\
\hline Direct & 0.03 & 0.08 & $-0.12-0.19$ & $0.16^{*}$ & 0.06 & $0.04-0.28$ & 0.06 & 0.04 & $-0.02-0.14$ \\
\hline Indirect & $0.36^{* * *}$ & 0.06 & $0.24-0.48$ & $0.34^{* * *}$ & 0.04 & $0.26-0.42$ & $0.12^{* * *}$ & 0.03 & $0.06-0.18$ \\
\hline
\end{tabular}

${ }^{\mathrm{a}} \mathrm{F}(2,312)=18.26 ; \mathrm{p}=0.001 ; \mathrm{R}^{2}=0.06$

${ }^{\mathrm{b}} \mathrm{F}(2,312)=58.59 ; \mathrm{p}=0.001 ; \mathrm{R}^{2}=0.16$.

${ }^{\mathrm{c}} \mathrm{F}(2,308)=15.76 ; \mathrm{p}=0.001 ; \mathrm{R}^{2}=0.05$.

$\mathrm{B}$ - non-standardized coefficient; SE - standard error; CI - confidence interval.

* $\mathrm{p}<0.05 ;{ }^{* *} \mathrm{p}<0.01 ; * * \mathrm{p}<0.001$.

Table 3. Total, direct and indirect effects of job demands on physical symptoms

\begin{tabular}{|c|c|c|c|c|c|c|c|c|c|}
\hline \multirow{3}{*}{ Effect } & \multicolumn{9}{|c|}{ Physical symptoms as a dependent variable } \\
\hline & \multicolumn{3}{|c|}{ interpersonal conflict at work ${ }^{\mathrm{a}}$} & \multicolumn{3}{|c|}{ organizational constraints $^{\mathrm{b}}$} & \multicolumn{3}{|c|}{ quantitative workload $^{c}$} \\
\hline & B & SE & $95 \% \mathrm{CI}$ & B & SE & $95 \% \mathrm{CI}$ & B & SE & $95 \% \mathrm{CI}$ \\
\hline Total & $0.16^{* * *}$ & 0.04 & $0.08-0.23$ & $0.14 * * *$ & 0.03 & $0.08-0.19$ & $0.05^{*}$ & 0.02 & $0.01-0.09$ \\
\hline Direct & 0.06 & 0.04 & $-0.02-0.14$ & 0.03 & 0.03 & $-0.02-0.11$ & 0.01 & 0.04 & $-0.02-0.06$ \\
\hline Indirect & $0.10^{* *}$ & 0.02 & $0.07-0.14$ & $0.11^{* *}$ & 0.04 & $0.06-0.13$ & $0.04^{*}$ & 0.01 & $0.02-0.07$ \\
\hline
\end{tabular}

${ }^{a} \mathrm{~F}(3,312)=17.36 ; \mathrm{p}=0.001 ; \mathrm{R}^{2}=0.05$.

${ }^{\mathrm{b}} \mathrm{F}(3,312)=24.58 ; \mathrm{p}=0.001 ; \mathrm{R}^{2}=0.07$.

${ }^{\mathrm{c}} \mathrm{F}(3,308)=6.6 ; \mathrm{p}=0.05 ; \mathrm{R}^{2}=0.02$.

Other abbreviations as in Table 2.

bottom lines, path a and $\mathrm{b}$. The hypothesis 2 has also been supported partially.

\section{DISCUSSION}

This research on the direct and indirect - mediated by the job burnout - effects of job demands on ill health has been conducted by means of tests. The JD-R model [4] has been the theoretical framework of the study. In line with the energetic process described by the authors of the model, job burnout mediates the negative effects of high job demands on the health problems. The authors acknowledge that the direct impact of job demands on health trouble is observed but they also highlight the mediating role of job burnout. Contrary to my expectations, the obtained results have fully confirmed the indirect effects and the direct effects of job demands - only partially. Only one of the 6 analyzed direct effects of job demands (the effect of organizational constraints on depression) has turned out to be statistically significant, whereas all the 6 indirect effects have been supported. Job burnout mediates negative effects of 3 job demands on both mental (H1) and physical (H2) health. It should be emphasized that interpersonal conflicts and organizational constraints are connected with job burnout stronger than with workload. It coincides with the report by Keenan et al. [13].

In conclusion, it seems that the data that has been obtained strongly support the indirect rather than the direct effects of job demands. The results are consistent with the JD-R model and suggest further exploration of the regulating role of job burnout. Similar results, with reference to mental health, have been found in Dutch [18] and Finnish [6] studies. Two investigations of the mediating role 


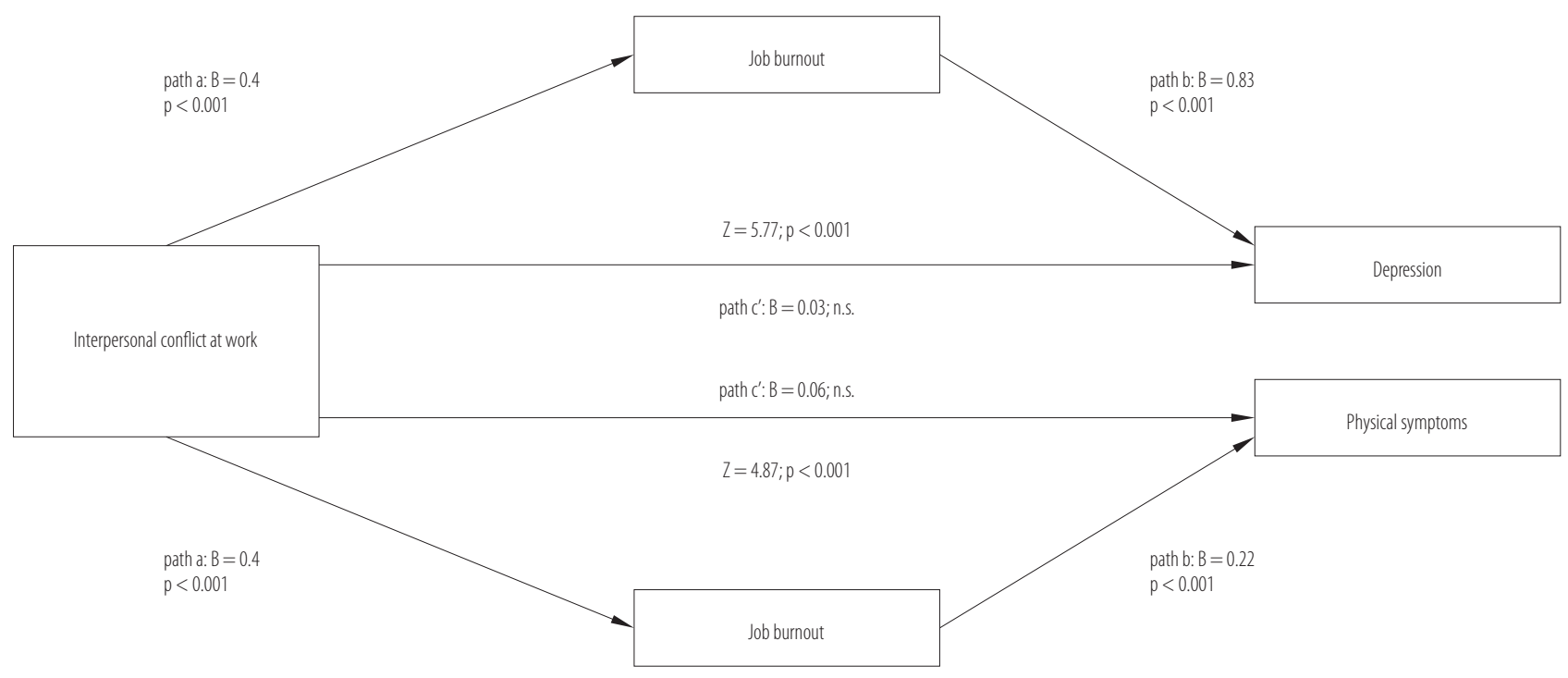

B - non-standardized coefficient; Z - Sobel test; n.s. - not statistically significant.

Fig. 1. Mediating effect of job burnout in the link between interpersonal conflict and ill health

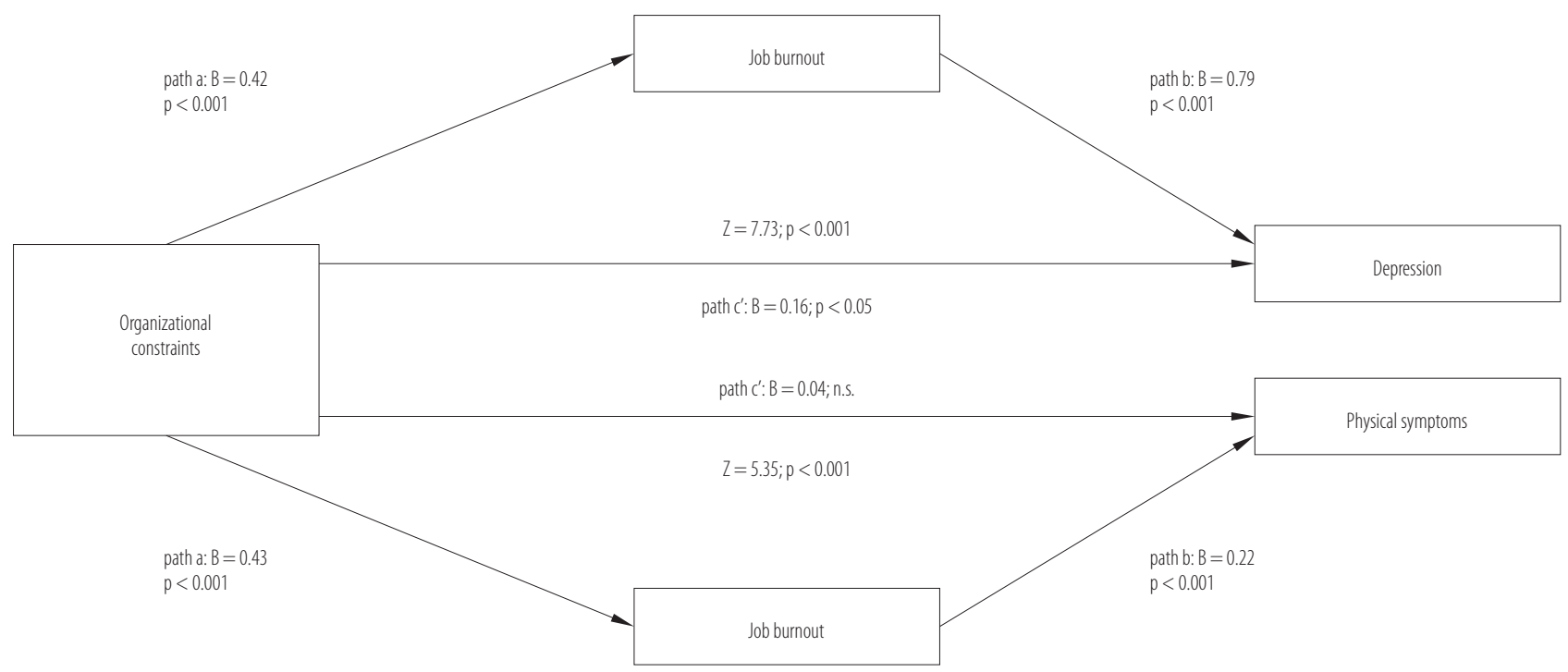

Abbreviations as in Figure 1.

Fig. 2. Mediating effect of job burnout in the link between organizational constraints and ill health

of job burnout in relation to physical health have yielded incoherent results [19], so, in this context, the data that has been obtained seem to be valuable. Some newer Israeli studies have also pointed out strong associations of job burnout with physical ailments such as musculoskeletal pain [28] and coronary heart disease [29].
When investigating the sources of diversity in the adverse impact of different job demands on health problems, it is worth referring to the well-known distinction of job stressors between 2 categories - challenge stressors and hindrance stressors [30]. The challenge stressors entail those of job demands which can be perceived by employees as 


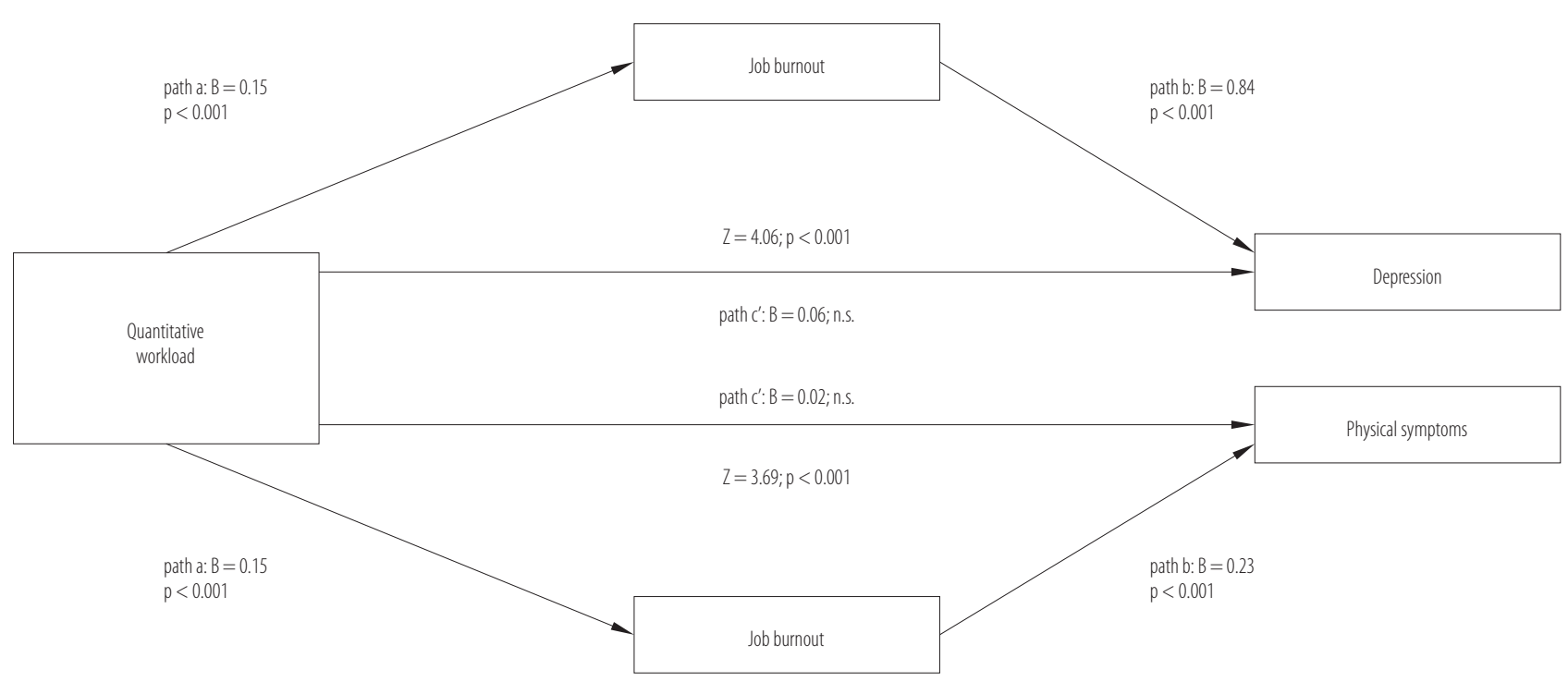

Abbreviations as in Figure 1.

Fig. 3. Mediating effect of job burnout in the link between quantitative workload and ill health

factors enabling personal development, gaining experiences and expanding knowledge. Contrary to it, the hindrance stressors are connected with those job demands which interfere with other job tasks, engage a lot of energy and deteriorate personal growth. The workers almost always react to the hindrance stressors with negative emotions which consequently worsen their well-being. On the other hand, the employees can react to the challenge stressors with either negative or positive emotions. It has been observed by the use of meta-analysis where hindrance stressors (e.g., role conflicts, organizational constraints) have negative correlation with job satisfaction, and challenge stressors (e.g., a variety of job tasks, quantitative workload) have positive correlation with it. Perhaps, in my study workload has been partially regarded as a challenge stressor and this is why its connection with poor health has been relatively weaker.

\section{CONCLUSIONS}

In the light of these results it can be concluded that job demands have a stronger effect on mental health than on physical health. The clearest connections have been observed between organizational constraints and depression.
Moreover, it is worth considering the differences in general effect sizes. The proportion of variance explained by 6 models varies from $2 \%$ (workload as a predictor of physical symptoms) to $16 \%$ (organizational constraints as a predictor of depression). Such data may be especially useful for managerial practice. It can be assumed intuitively that organizational constraints may be stronger when controlled by an organization and may be easier modified with the procedures than the interpersonal relations or workload. Poor equipment, organizational rules and procedures, inadequate training, and incorrect instructions quite highly come under control of the management.

To the best of my knowledge all researchers have taken into account only general job burnout as the mediator. It is interesting in what way separate components of job burnout i.e., exhaustion and disengagement from work mediate the relationship between job demands and mental as well as physical health problems. One of the studies has shown that while exhaustion - the so-called root of job burnout - is associated with high job demands, disengagement from work is related to low level of job resources [4]. Moreover, in line with several studies, exhaustion 
is the predictor of mental (e.g., depression, anxiety) and physical (e.g., heart coronary disease, gastric problems) health problems $[28,29]$. It seems more likely that exhaustion mediates the link between job demands and ill health to a greater extent than disengagement from work.

Taking the obtained results into consideration in terms of the JD-R model, it is plausible to state how important the role of job resources is. They have not been taken into account in the presented analyses but their beneficial functions are distinctly emphasized by the authors of the JD-R model. The authors accentuate that health problems do not represent the immediate response to job demands but they are modified by employees' job resources. Numerous studies have concluded that job resources such as social support, job autonomy, received feedback, opportunities for development and coaching may buffer the adverse impact of job demands on poor health [5]. Beneficial functions of job resources are particularly clearly confirmed in the case of emotional demands.

To sum up, it should be also noted that this research contains certain limitations which weaken its external validity and call for caution in the interpretation of the results. Unequal sex ratio in the sample with almost $80 \%$ female participants is one of the limitations. The data may apply to men to a lesser extent. What is more, the research has taken into consideration only one (and quite specific) occupational group - teachers.

Another constraint results from the fact that mediation analyses have been based on the results of the cross-sectional study instead of the cross-lagged study or those obtained from experimental research. Both job burnout and health problems are usual dynamic processes which evolve being subjected to a long-term impact of stressors and resources, therefore it is crucial to reflect their gradual development and - as Hobfoll [30] has stated - "a spiral of reciprocal relationships." This can be achieved only through longitudinal research with a several month break between test and retest. Thus, this type of study would be specifically recommended in the course of further examination of the correlation between the phenomena analyzed in this study.

\section{REFERENCES}

1. Kompier MAJ. New systems of work organization and workers' health. Scand J Work Environ Health. 2006;32:421-30, http://dx.doi.org/10.5271/sjweh.1048.

2. Hellgren J, Sverke M, Naswall K. Changing work roles: New demands and challenges. In: Naswall K, Hellgren J, Sverke $\mathrm{M}$, editors. The individual in the changing working life. New York: Cambridge University Press; 2008. p. 46-66, http:// dx.doi.org/10.1017/CBO9780511490064.003.

3. Balducci C, Schaufeli WB, Fraccaroli F. The job demandsresources model and counterproductive work behaviour: The role of job-related affect. Eur J Work Organ Psychol. 2011;20(4):467-96, http://dx.doi.org/10.1080/135943210 03669061.

4. Demerouti E, Bakker AB, Nachreiner F, Schaufeli WB. The job demands resources model of burnout. J Appl Psychol. 2001;86(3):499-512, http://dx.doi.org/10.1037//00219010.86.3.499.

5. Bakker AB, Demerouti E, Taris TW, Schaufelli WB, Schreurs PJG. A multigroup analysis of the job demands-resources model in four home care organizations. Int J Stress Manag. 2003;10(1):16-38, http://dx.doi.org/10.1037/1072-5245.10.1.16 6. Hakanen JJ, Bakker AB, Schaufeli WB. Burnout and work engagement among teachers. J Sch Psychol. 2006;43(6): 495-513, http://dx.doi.org/10.1016/j.jsp.2005.11.001.

7. Hakanen JJ, Schaufeli WB, Ahola K. The job demandsresources model: A three-year cross-lagged study of burnout, depression, commitment and work engagement. Work Stress. 2008;22(3):224-41, http://dx.doi. org/10.1080/02678370802379432.

8. Hockey GRJ. Cognitive-energetical control mechanism in the management of work demands and psychological health. In: Baddely A, Weiskrantz L, editors. Attention: Selection, awareness and control. Oxford, England: Clarendon Press; 1993. p. 328-45. 
9. Baka L. [The effects of job demands and job resources on job burnout and work engagement in group of teachers]. Częstochowa: Wydawnictwo Akademii im. Jana Długosza w Częstochowie; 2013. Polish.

10. Abel MH, Sewell J. Stress and burnout in rural and urban secondary school teachers. J Educ Res. 1999;92(5):287-93, http://dx.doi.org/10.1080/00220679909597608.

11. Mearns J, Cain JE. Relationships between teachers occupational stress and their burnout and distress: Roles of copying and negative mood regulation expectancies. Anxiety Stress Coping. 2003;16(1):71-82, http://dx.doi.org/10.1080/1061580 021000057040.

12. Spector PE, Jex SM. Development of four self-report measures of job stressors and strain: Interpersonal conflict at Work Scale, Organizational Constraints Scale, Quantitative Workload Inventory and Physical Symptoms Inventory. J Occup Health Psychol. 1998;3(4):356-67, http://dx.doi. org/10.1037/1076-8998.3.4.356.

13. Keenan A, Newton TJ. Stressful events, stressors and psychological strains in young professional engineers. J Organ Behav. 1985;6(2):151-6, http://dx.doi.org/10.1002/job. 4030060206.

14. Bruk-Lee V, Spector PE. Interpersonal conflict and stress at work: Implications for employee health and well-being. In: Rossi AM, Perrewe PL, James AM, editors. Coping and prevention. Charlotte, US: Information Age Publishing; 2012. p. 3-22.

15. Liu C, Nauta MM, Li CP, Fan JY. Comparisons of organizational constraints and their relationships to strains in China and the United States. J Occup Health Psychol. 2010;15(4):452-67, http://dx.doi.org/10.1037/a0020721.

16. Häusser JA, Mojzisch A, Niesel M, Schulz-Hardt S. Ten years on: A review of recent research on the Job Demand-Control (-Support) model and psychological well-being. Work Stress. 2010;2(1)4:1-35, http://dx.doi. org/10.1080/02678371003683747.

17. Maslach C, Schaufelli WB, Leiter MP. Job burnout. Ann Rev Psychol. 2001;52:397-422.
18. Schaufelli WB, Bakker AB. Job demands, job resources and their relationship with burnout and engagement: A multisample study. J Organ Behav. 2004;25(3):293-315, http:// dx.doi.org/10.1002/job.248.

19. Korunka C, Kubicek B, Schaufeli WB, Hoonakker P. Work engagement and burnout: Testing the robustness of the Job Demands-Resources model. J Posit Psychol. 2009;4(3): 243-55, http://dx.doi.org/10.1080174339760902879976.

20. Basińska BA, Wilczek-Rużyczka E. The role of rewards and demands in burnout among surgical nurses. Int J Occup Environ Health. 2013;26(4):593-604, http://dx. doi.org/10.2478/s13382-013-0129-8.

21. Baka L, Cieślak R. [Self-efficacy and social support and the effects of job stressors on job burnout and work engagement in teachers]. Studia Psychol. 2010;48:5-18. Polish.

22. Friedman IA, Farber BA. Professional self-concept as a predictor of teacher burnout. J Educ Res. 1992;86(1):28-35, http://dx.doi.org/10.1080/00220671.1992.9941824.

23. Demerouti E, Bakker AB, Vardakou I, Kantas A. The convergent validity of two burnout instruments. Eur J Psychol Assess. 2003;19(1):12-23, http://dx.doi.org/10.1027//1015-5759.19.1.12.

24. Baka L. [Relationships between work-family and familywork conflicts and health of nurses - Buffering effects of social support]. Med Pr. 2013;64(6):775-84, http://dx.doi. org/10.13075/mp.5893.2013.0068. Polish.

25. Beck AT, Weissman A, Lester D, Trexler L. The measurement of pessimism: The Hopelessness Scale. J Consult Clin Psychol. 1974;42(6):861-5, http://dx.doi.org/10.1037/h0037562.

26. Hayes AF. An introduction to mediation, moderation, and conditional process analysis: A regression-based approach. New York: Guilford Press; 2013.

27. Baron RM, Kenny DA. The moderator - Mediator variable distinction in social psychological research: Conceptual, strategic and statistical considerations. J Pers Soc Psychol. 1986;51(6):1173-82, http://dx.doi.org/10.1037/00223514.51.6.1173.

28. Lindeberg SI, Rosvall M, Östergren PO. Exhaustion predicts coronary heart disease independently of symptoms of 
depression and anxiety in men but not in women. J Psychosom Res. 2012;72(1):17-21, http://dx.doi.org/10.1016/j.jpsychores.2011.09.001.

29. Lindblom KM, Linton SJ, Fedeli C, Bryngelsson IL. Burnout in the working population: Relations to psychosocial work factors. Int J Behav Med. 2006;13(1):51-9.
30. Hobfoll SE. [Stress culture and society]. Gdańsk: Gdańskie Wydawnictwo Psychologiczne; 2006. Polish.

This work is available in Open Access model and licensed under a Creative Commons Attribution-NonCommercial 3.0 Poland License - http://creativecommons.org/ licenses/by-nc/3.0/pl/deed.en. 